\title{
MULTI-CRITERIA DECISION-MAKING MODEL FOR ASSESSING THE SUSTAINABILITY INDEX OF WIND-TURBINE SUPPORT SYSTEMS: APPLICATION TO A NEW PRECAST CONCRETE ALTERNATIVE
}

\author{
Albert de la FUENTE ${ }^{\mathrm{a}}$, Jaume ARMENGOU ${ }^{\mathrm{b}}$, Oriol PONS ${ }^{\mathrm{a}}$, Antonio AGUADO ${ }^{\mathrm{a}}$ \\ ${ }^{a}$ Universitat Politècnica de Catalunya (UPC), BarcelonaTech., Jordi Girona Salgado 1-3, \\ C1-202c, 08034, Barcelona, Spain \\ ${ }^{b}$ Universitat Internacional de Catalunya (UIC), Immaculada 22, 08017, Barcelona, Spain
}

Received 12 Feb 2014; accepted 08 Oct 2014

\begin{abstract}
A multi-criteria decision-making system based on the MIVES method is presented as a model for assessing the global sustainability index scores of existing wind-turbine support systems. This model is specifically designed to discriminate between tower systems in order to minimize the subjectivity of the decision and, thus, facilitate the task of deciding which system is best for a given set of boundary conditions (e.g., height, turbine power, soil conditions) and economic, social and environmental requirements. The model's versatility is proven by assessing the sustainability index of an innovative new precast concrete tower alternative also described in this paper. As a result of this analysis, some points of improvement in the new system have been detected.
\end{abstract}

Keywords: AHP, wind-turbine supports, MIVES, quantitative analysis, sustainability, value analysis.

\section{Introduction}

Wind farms are an environmentally-friendly energy-production solution offering attractive economic returns and growing social acceptance. It is thus no surprise that their outlook for the future is so bright. They are projected to grow $60 \%$ over the next 10 years (Hameed et al. 2011), and this growth is expected to be exponential, such that by 2020 the world will have a total installed capacity of 1 million MW (Gsänger, Pitteloud 2012). In some countries, such as Spain, the current installed wind power capacity was already enough to meet up to $22 \%$ of the average annual electricity demand in 2013 .

At present, several types of wind turbines can be used on wind farms to generate large amounts of electricity (up to $7.5 \mathrm{MW}$ per turbine). The most common is the three-bladed horizontal-axis wind turbine, the main components of which are a rotor, a nacelle, and a tower used to elevate the electrical components to the design height and transfer the loads to the foundation (Manwell et al. 2002).

Most of the construction alternatives are made up of concrete and/or steel, which are the resistant materials, and the technical industry and the market itself have established application ranges for them. Table 1 shows the main alternatives with their primary applications, advantages, and disadvantages (de la Fuente 2007).
As shown in Table 1, concrete towers can be classified according to how they are built: in situ (Villar 2004) or precast (Vries 2009). In some cases, both techniques are used for the same tower (Lofty 2012), and towers may even be precast on site if the number of towers justifies the expense. With in situ concrete solutions, passive steel bars are used to reinforce the concrete and limit the width of the potential cracks. In contrast, active reinforcement is used with precast concrete towers. The concrete modules are pre-stressed in plant to reduce the probability of cracking during both the transient load phases (e.g., demoulding, transport and handling) and the service life. These modules are subsequently connected by means of one of the various post-tensioning systems on the market.

The all-steel solutions are either tapered tubular towers or lattice structures. Tapered tubular towers dominate the market for heights of less than $80 \mathrm{~m}$ (Agbayani, Vega 2012). This is because the optimal quality and quantity of the material used, the ease of transport, and their quick installation makes them very competitively priced. However, for heights of more than $80 \mathrm{~m}$, such as those examined here, this alternative presents fewer advantages and is less competitive. For their part, lattice towers are made up of steel sections bolted and/or welded together in situ to accommodate a very broad range of heights from $60 \mathrm{~m}$ to, e.g., the $140 \mathrm{~m}$ reached by the tower in Spremberg,

Corresponding author: Albert de la Fuente

E-mail: albert.de.la.fuente@upc.edu 
Table 1. Applications, advantages, and disadvantages of current tower technologies

\begin{tabular}{|c|c|c|c|c|c|}
\hline & \multicolumn{2}{|r|}{ Steel } & \multicolumn{2}{|c|}{ Concrete } & \multirow{2}{*}{ Hybrid } \\
\hline & Lattice & Tubular & In situ & Precast & \\
\hline Tower height, $h(\mathrm{~m})$ & $60-160$ & $60-120$ & $60-115$ & $80-120$ & $80-146$ \\
\hline Base diameter, $D(\mathrm{~m})$ & Unlimited & $3.0-4.5$ & $3.0-8.5$ & $3.0-5.0$ & $3.0-5.0$ \\
\hline Aspect ratio $(h / \Phi)$ & Variable & $17-27$ & $10-20$ & $10-20$ & $10-20$ \\
\hline Module thickness, $t(\mathrm{~m})$ & Variable & $0.025-0.050$ & $>0.18$ & $>0.15$ & $\begin{array}{l}<0.030 ;>0.15 \\
\text { steel; concrete }\end{array}$ \\
\hline Weight/height, $t / \mathrm{m}$ & $2-3$ & $2-5$ & \multicolumn{2}{|c|}{$8-19$} & $3-15$ \\
\hline \multirow[t]{2}{*}{ Advantages } & $\begin{array}{l}\text { Fewer } \\
\text { transportation } \\
\text { constraints }\end{array}$ & $\begin{array}{l}\text { Less material and } \\
\text { optimal transport for } \\
h<80 \mathrm{~m}\end{array}$ & \multicolumn{2}{|c|}{$\begin{array}{l}\text { Structural stiffness } \\
\text { Vibration frequencies far from } \\
\text { those of electrical systems } \\
\text { Durability }\end{array}$} & $\begin{array}{l}\text { Intended to mitigate } \\
\text { disadvantages of } \\
\text { previous technologies }\end{array}$ \\
\hline & \multicolumn{2}{|c|}{$\begin{array}{l}\text { Quick installation } \\
\text { (tub. usually quicker than latt.) }\end{array}$} & Monolithic system & $\begin{array}{l}\text { Quick } \\
\text { installation }\end{array}$ & \\
\hline & \multicolumn{2}{|c|}{$\begin{array}{l}\text { Joints vulnerability } \\
\text { Low fire resistance }\end{array}$} & $\begin{array}{l}\text { Weather conditions } \\
\text { vulnerability }\end{array}$ & \multirow{2}{*}{$\begin{array}{l}\text { Joints } \\
\text { vulnerability } \\
\text { Transport and } \\
\text { erection costs }\end{array}$} & \multirow[t]{2}{*}{ In experimental stage } \\
\hline Disadvantages & & $\begin{array}{l}\text { transport \& erection } \\
\text { costs } \\
h>80 \mathrm{~m}\end{array}$ & & & \\
\hline Geometry & Lattice & Truncated cone & & & \\
\hline
\end{tabular}

Germany (Ernst, Verlag 2014). Finally, there are hybrid solutions, such as the tower built in Grevenbroich (Germany) to support a $2.3 \mathrm{MW}$ wind turbine. That tower consists of a lower segment made of precast concrete (82 $\mathrm{m})$, which absorbs the high forces at the intersection between the tower and the foundation, and an upper segment made out of welded steel $(51 \mathrm{~m})$, which is subject to fewer stresses and enables faster installation.

It is worth noting that, although tower heights of over $120 \mathrm{~m}$ are technically possible, with the exception of experimental prototypes, they are quite rare.

This paper is focused on on-shore towers and, in particular, on the different construction methods and material combinations available today for the installation of such structures for heights of between 100 and $120 \mathrm{~m}$. This height range is associated with the use of large wind turbines $(\mathrm{P} \geq 3.0 \mathrm{MW})$, which are currently experiencing rapid growth due to their technical, economic, and environmental advantages (Engström et al. 2010). The study also includes the foundation structure, as the construction method and materials used to build the tower affect the size and shape thereof and, thus, the volume of material required, the deadlines, and the installation costs. This analysis strategy makes it possible to differentiate between the various possible tower types based on installed power and tower height requirements.

The tower types shown in Table 1 include a wide range of construction processes and material combinations, some of which have not yet been implemented but have considerable future potential. Each alternative thus has strengths and weaknesses; however, there is not yet a model (or, if there is, it has not been reported in the literature) that enables a holistic assessment to determine which one would be the most sustainable for a given set of turbine height and electrical power requirements based on economic, technical, environmental, and social criteria.

This paper aims to present a model for assessing the sustainability of wind turbine towers (regardless of construction process, materials, height, and turbine size). This assessment will be conducted using a multi-criteria analysis method called the Integrated Value Model for Sustainable Assessment (or MIVES from the Spanish), which makes it possible to take into account the three main pillars of sustainability and can be used as a decision-making model by stakeholders.

To this end, first, a new precast concrete tower alternative for large wind turbines is presented. This windturbine support system is then used as an example of the application of the proposed sustainability assessment model. Its consideration in this paper was chosen to avoid conflicts of interest with other existing alternatives since, although it has been patented, it is still under development. Moreover, the authors are familiar with the system's technical and economic specifications.

The presentation of this new system will be followed by a detailed explanation of the new assessment model, including the rationale for its requirement tree, weightings, and value functions. The new tower construction system's sustainability will then be assessed through the calculation of its sustainability index score and the satisfaction scores for each indicator. Finally, conclusions will be drawn regarding the proposed analysis method and its suitability as a model for assessing wind turbine tower alternatives. 


\section{New tower concept for supporting large wind turbines}

In order to propose a new alternative for supporting large turbines $(\mathrm{P} \geq 3.0 \mathrm{MW})$ and to take advantage of the better wind quality at greater heights, a three-legged tower was designed consisting of precast concrete modules joined with a post-tension system in the form of high-resistance steel bars. The three legs are reinforced transversely with steel profiles, creating a tripod able to reach heights of $100-120 \mathrm{~m}$ (see Fig. 1). This system is the subject of Spanish patent No. 7,123,455 (Armengou 2009).

The geometry and structure of the tower were designed to meet the following requirements:

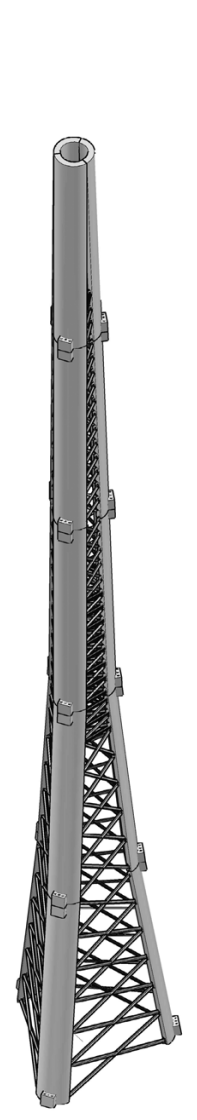

a)

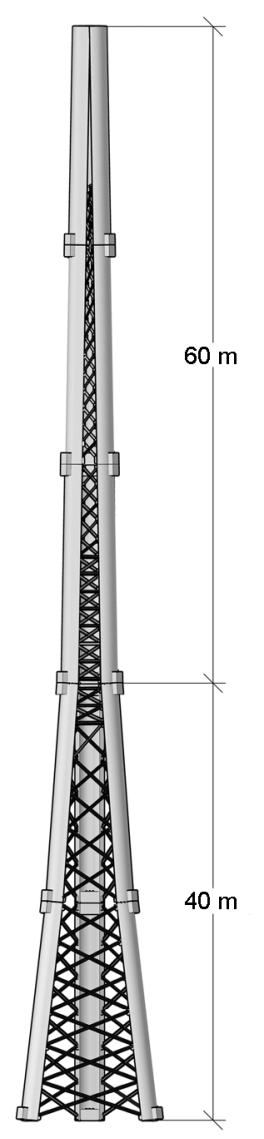

b)

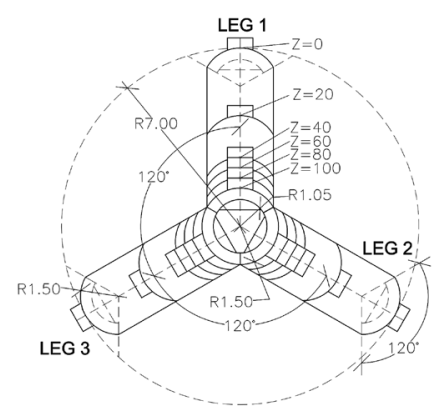

c)
1. A tower top diameter of $3.0 \mathrm{~m}$ (Fig. 1c), as specified by the manufacturer of the turbine the tower would potentially support. Moreover, because the top had to be circular, the cross-section of each module had to span a $120^{\circ}$ section of the circumference.

2. All modules had to have the same transverse and longitudinal geometry: (1) so that a single formwork could be used to cast all the pieces, thereby ensuring swift recovery of the initial investment in molds; (2) and to make the tower's assembly as straightforward as possible.

3. A maximum module length of $20 \mathrm{~m}$ (with 15 or 18 modules for the $100 \mathrm{~m}$ and $120 \mathrm{~m}$ towers, respectively) so as not to excessively increase transport and crane costs and needs.

- Possibility of installing blades up to $60 \mathrm{~m}$ long (swept area diameter of $120 \mathrm{~m}$ ) while at the same time ensuring a minimum separation of one meter between the blade and the tower so as to prevent contact between them should the blades be bent by extreme winds. As can be seen in the frontal view (Fig. 1b), this constraint meant that the top $60 \mathrm{~m}$ of the tower had to be entirely upright, leaving only 40 meters available to expand the diameter and, thus, maximize structural stiffness.

- An oscillation frequency for the first mode of vibration higher than $0.4 \mathrm{~Hz}$ to ensure the stiffness of the structure as a whole and prevent coupling with the natural frequency of the electrical equipment.

The design of the solution presented in Figure 1 took all these considerations into account. Additionally, economic and technical feasibility studies, as well as studies on process optimization and foundation components, were conducted and reported in de la Fuente (2007) and Herrando (2012).

Ultimately, the tower shown in Figure 1 was designed to meet all the aforementioned requirements, using the benchmark standards for actions on structures (EC-1) and for the design of concrete structures (MC-2010) and steel structures (EC-4), as well as the SAP2000 ${ }^{\circledR}$ (Berkeley) and AES (de la Fuente et al. 2012) models for the structural and sectional calculation.

The design resulted in modules that are $20 \mathrm{~m}$ long and weigh a total of $600 \mathrm{kN}$ (Fig. 2). They are joined together by means of a continuous post-tensioned system, installed in situ by means of 6 Macalloy bars, each with a diameter of $75 \mathrm{~mm}$. Furthermore, in order to prevent the concrete from cracking during assembly or in the worstcase wind scenarios, the modules are pre-stressed at the plant using 100 Y1860-S7 steel quality 0.6 " - diameter tendons (Fig. 3a). This active reinforcement is supplemented with passive reinforcement (Fig. 3b) to compensate for strong fatigue phenomena and expected cracking, since the geometric configuration of the legs enables them to work compressed or tensioned, depending which way the wind is acting. The active and passive reinforcement configuration is the same for all modules, thereby facili-

Fig. 1. Three-legged tower 


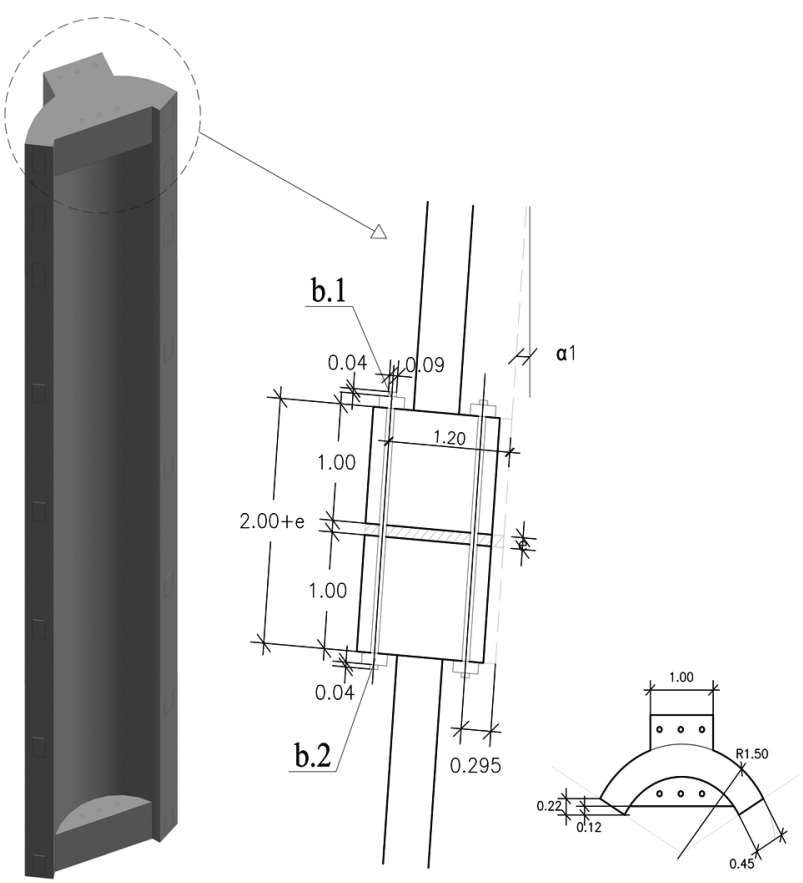

Fig. 2. Module

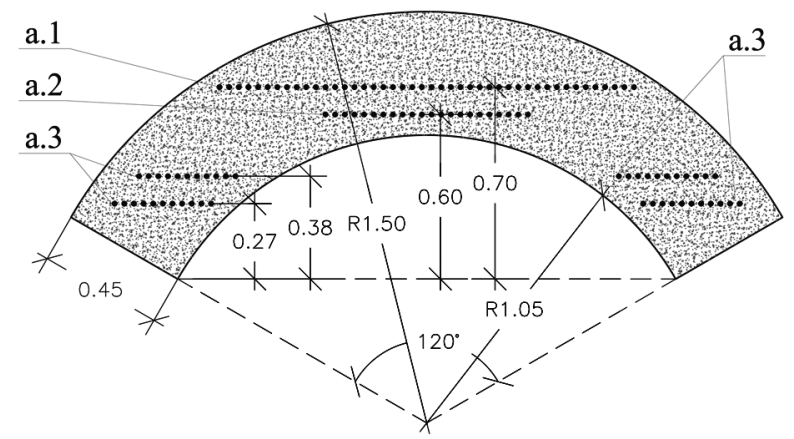

a)

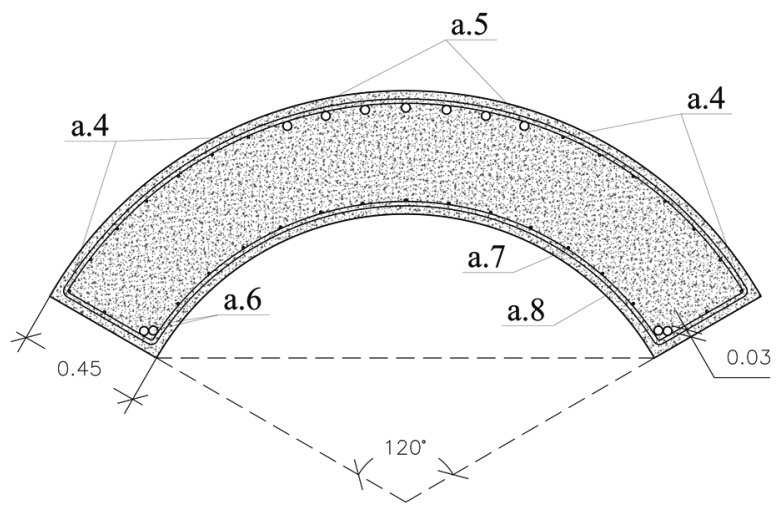

b)

Fig. 3. Reinforcement of the modules tating on-site steel-fixing work and preventing the serious drawbacks that would ensue from incorrectly positioning a module that had a different type of reinforcement. In any case, the reinforcement can always be optimized to minimize the use of materials and the cost of this item.

The structural analyses of the tower show that it is a stiff structure with a vibration frequency of the first period of $0.42 \mathrm{~Hz}$ and a peak displacement at the top of $400 \mathrm{~mm}$ under the worst wind conditions. Likewise, the results confirm that the designed tower is sufficient to support a $3.5 \mathrm{MW}$ turbine at heights of up to $120 \mathrm{~m}$. Table 2 gathers a summary of the tripod's main features (de la Fuente 2007).

Table 2. Values of the main features of the proposed tripod tower (100 m height)

\begin{tabular}{lcc}
\hline \multicolumn{1}{c}{ Feature } & Value & Unit \\
\hline Height & 100 & $\mathrm{~m}$ \\
Power output of supported & 3.5 & $\mathrm{MW}$ \\
turbine & & \\
Foundation weight & 698 & $\mathrm{t} /$ tower \\
Tower weight & 1,263 & $\mathrm{t} /$ tower \\
Construction cost & $1,022,000$ & $€ /$ tower \\
Maintenance cost & 6,545 & $€ /$ tower $\cdot$ year \\
Deconstruction cost & 120,200 & $€ /$ tower \\
Energy consumption (LCA) & 0.68 & $\mathrm{GWh}^{\prime} /$ tower \\
$\mathrm{CO}_{2}$ emissions (LCA) & 299 & $\mathrm{TnCO}_{2}$-e/tower \\
\hline
\end{tabular}

Finally, as shown in Figure 4, the tower's foundation (de la Fuente 2007; Herrando 2012) was designed with a hexagon plan inscribed in a $22 \mathrm{~m}$ diameter circle and has a variable depth of between 0.5 and $1.5 \mathrm{~m}$. This strategy makes it possible to maximize resistance to the overturning bending moment that might occur should it
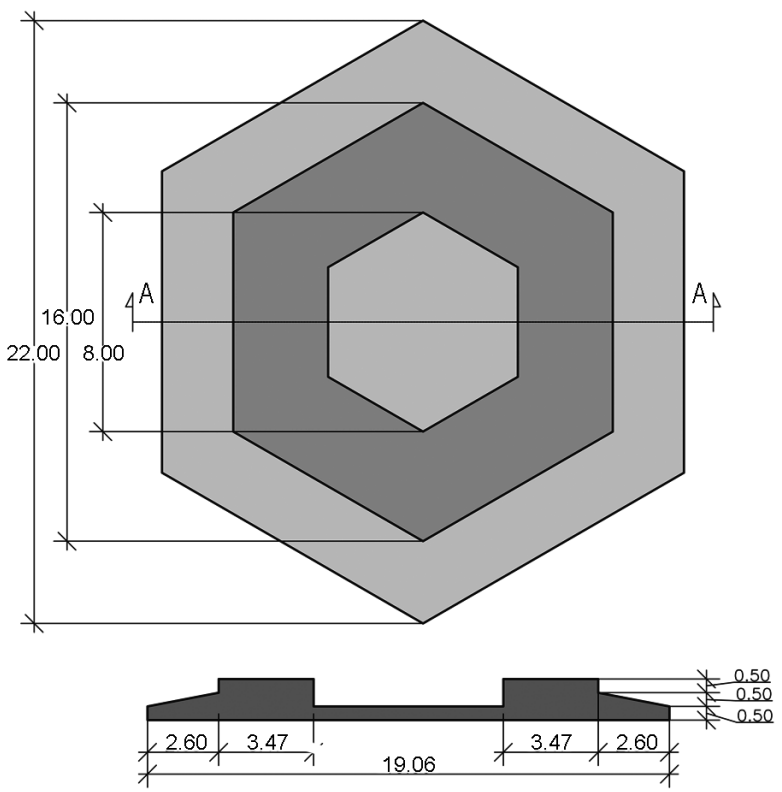

Fig. 4. Tower's foundation 
become partially detached in situations of extreme wind while, at the same time, minimizing the weight. Moreover, a hexagonal geometry has been shown to allow this type of tripod support structure to withstand wind loads optimally across the spectrum.

\section{Sustainability assessment model for wind towers}

The model used in this paper, based on the MIVES method, uses value functions (Alarcón et al. 2011) to quantitatively assess various alternatives for meeting a single need and to reduce the subjectivity of the decision-making process. This strategy has been used previously in other areas of decision-making and, in particular, in relation to structures for: 1) the choice of the optimal tunnel diameter for the L9 line of the Barcelona subway system (Ormazabal et al. 2008); 2) the method proposed in the Spanish Code on Structural Concrete (EHE-08) (CPH 2008) to assess the sustainability of concrete structures (Aguado et al. 2012), to which improvements have already been proposed in order to take into consideration existing natural uncertainties in the planning and feasibility study stage (del Caño et al. 2012); 3) the assessment of alternatives for the production of concrete columns for use in construction in terms of construction method, geometry and mechanical resistance (Pons, de la Fuente $2013)$; 4) the assessment of building design alternatives, giving special consideration to losses due to natural hazards (Mosalam et al. 2012); and 5) assessing sustainability in the construction industry based on occupational health and safety criteria (Reyes et al. 2014).

To use the proposed model to assess sustainability performance and/or analyze alternatives, it is necessary first to define a requirement tree and to assign relative weights to each assessment parameter. The tree must have a minimum number of indicators, which must be representative and independent of each other, to ensure that, together with the assigned weights, it offers a reliable assessment scenario that enables the systematic ranking of possible alternatives (in this case, types of wind turbine towers) while at the same time reducing subjectivity.
To begin the assessment process, seminars were held with experts in each of the specific subjects related to the field of wind turbine towers aimed at defining the requirement tree. The weightings of the tree's various components were also defined at these seminars, using the analytic hierarchy process (AHP) (Saaty 1990; Nyström, Söderholm 2010) and/or direct assignment.

The requirement tree and established process must moreover be accompanied by certain equal and homogeneous system constraints that reflect the range of analysis. In this paper, the established constraints are a tower height of between 100 and $120 \mathrm{~m}$, an on-shore tower type with a $3.5 \mathrm{MW}$ turbine, and a maximum transportation distance of $350 \mathrm{~km}$ (Engström et al. 2010).

Table 3 shows the requirement tree defined through the process described above. The tree includes only those requirements, criteria and indicators most necessary and relevant to differentiating between wind turbine supportstructure towers, including the foundation.

The tree includes the three main sustainability requirements $\mathrm{R}_{\mathrm{i}}$, which, in turn, are divided into a total of 11 discrete indicators $\mathrm{I}_{\mathrm{i}}$ with a view to encompassing technological and functional aspects. The economic requirement $\left(R_{1}\right)$ takes into account the impact of the different costs, both direct and indirect, identified during the seminars. The environmental requirement $\left(R_{2}\right)$ is used to consider the impact of the construction process and materials involved in the tower's installation. In this regard, it should be mentioned that wind farms have a lower environmental impact in terms of energy than electricitygeneration technologies based on fossil fuels. Furthermore, the difference between the energy produced and consumed is positive over the tower's entire life (Crawford 2009; Guezuraga et al. 2012; Ardente et al. 2008). The social requirement $\left(\mathrm{R}_{3}\right)$ is used to assess key factors for the social acceptance of wind farms.

The weightings of the requirements $\lambda\left(\mathrm{R}_{\mathrm{i}}\right)$ were assigned from the point of view of the sustainability, understood as a balance between the three requirements $\left(\lambda\left(\mathrm{R}_{\mathrm{i}}\right)=0.33 ; i=1,2,3\right)$ aligned with the Rio Declara-

Table 3. Requirements tree

\begin{tabular}{|c|c|c|c|}
\hline Requirement & Criteria & Indicator & Unit \\
\hline \multirow{4}{*}{$\begin{array}{l}\mathrm{R}_{1} \\
\text { Economic } \\
(33.3 \%)\end{array}$} & \multirow{2}{*}{$\mathrm{C}_{1}$ Construction cost $(40 \%)$} & $\mathrm{I}_{1}$ Direct cost $(50 \%)$ & $€ /$ tower \\
\hline & & $\mathrm{I}_{2}$ Cost deviations $(50 \%)$ & Points \\
\hline & $\mathrm{C}_{2}$ Maintenance cost $(40 \%)$ & $\mathrm{I}_{3}$ Cost of planned works $(100 \%)$ & $€ /$ tower \\
\hline & $\mathrm{C}_{3}$ Deconstruction $(20 \%)$ & $\mathrm{I}_{4}$ Deconstruction $(100 \%)$ & $€ /$ tower \\
\hline \multirow{3}{*}{$\begin{array}{l}\mathrm{R}_{2} \\
\text { Environmental } \\
(33.3 \%)\end{array}$} & $\mathrm{C}_{4}$ Resources $(33.33 \%)$ & $\mathrm{I}_{5}$ Material consumption $(100 \%)$ & $\mathrm{Tn} / \mathrm{MW}$ \\
\hline & $\mathrm{C}_{5}$ Energy $(33.33 \%)$ & $\mathrm{I}_{6}$ Energy consumption (100\%) & $\mathrm{GWh} / \mathrm{MW}$ \\
\hline & $\mathrm{C}_{6}$ Emissions $(33.33 \%)$ & $\mathrm{I}_{7} \mathrm{CO}_{2}$ emissions $(100 \%)$ & $\mathrm{TnCO}_{2}$-e/MW \\
\hline \multirow{3}{*}{$\begin{array}{l}\mathrm{R}_{3} \\
\text { Social } \\
(33.3 \%)\end{array}$} & $\mathrm{C}_{7}$ Occupational hazards $(30 \%)$ & $\mathrm{I}_{8}$ Risk of accident $(100 \%)$ & \multirow{3}{*}{ Points } \\
\hline & $\mathrm{C}_{8}$ Perception $(60 \%)$ & $\begin{array}{l}\mathrm{I}_{9} \text { Proportions }(50 \%) \\
\mathrm{I}_{10} \text { Customization }(50 \%)\end{array}$ & \\
\hline & $\mathrm{C}_{9}$ Technology integration $(10 \%)$ & $\mathrm{I}_{11}$ New patents $(100 \%)$ & \\
\hline
\end{tabular}


tion (UN 1992). Those weightings associated to the criteria and indicators were established by considering the recommendations gathered in the technical literature as well as the experience of the authors and the suggestions expressed by the different experts that participated in the seminars.

Had the analysis been performed from the point of view of either a private investor or a public owner, such as a local authority, the tree would be the same, but the weightings, mainly $\lambda\left(\mathrm{R}_{\mathrm{i}}\right)$, and the parameters associated to the value functions might vary depending on both the economic and social situation and the environmental awareness of the stakeholders; nevertheless, the same method would be used to determine them.

A parametric study was conducted to verify the proposed model's versatility with regard to assessing other scenarios based on different weighting strategies. The results are reported in the Section 3 below.

Requirement $R_{1}$ is primarily used to evaluate the construction, maintenance and deconstruction costs of both the support and the foundation according to criteria $\mathrm{C}_{1}, \mathrm{C}_{2}$ and $\mathrm{C}_{3}$, respectively. Installation time is not included in the criteria set for requirement $\mathrm{R}_{1}$, as it cannot be used to differentiate between alternatives when the end-goal is to install an entire wind farm. This is because, in general, the electrical equipment is installed sometime after the assembly work for the towers has been completed, and, thus, most of the time, the installation time does not affect the overall deadline for completing the wind farm as a whole.

Within requirement $\mathrm{R}_{1}$, greater weight is given to criteria $\mathrm{C}_{1}$ and $\mathrm{C}_{2}$, as they are used to assess the initial investment and amortization stages, respectively. To this end, $\mathrm{C}_{1}$ includes both the direct cost $\left(\mathrm{I}_{1}\right)$ and any deviations from it $\left(\mathrm{I}_{2}\right)$. Specifically, $\mathrm{I}_{1}$ includes the cost of the materials for the tower and the transportation thereof, as well as of the final structure's installation and assembly. $\mathrm{I}_{2}$ assesses the tower's sensitivity to variations in cost due to unfavorable weather conditions during the construction phase (e.g., the impact of low temperatures, which, in the case of in situ concrete, can lead to lower resistance and/ or a halt in the works, or of strong winds, which, in the case of precast systems, can hinder or impede the lifting and assembly of pieces with large surface areas). $\mathrm{I}_{3}\left(\mathrm{C}_{2}\right)$ reflects the cost of the scheduled work included in the maintenance plan proposed by the tower's manufacturer. And $\mathrm{I}_{4}\left(\mathrm{C}_{3}\right)$ assesses the cost of deconstructing the tower, either by dismantling it, when the construction method used so allows, or through its demolition.

Requirement $R_{2}$ is divided into three equallyweighted criteria: 1) the consumption of material resources for the tower's construction, considering only those structural materials for which alternatives are available; 2) energy consumption over the tower's life cycle, from its construction to its dismantling, including the energy consumption of the standard transportation and lifting equipment used today, optimizing its use and accounting for variations due to adverse weather conditions, subject to the maximum viable distances for each alternative; and 3 ) the tower's emissions over its life cycle, focusing especially on $\mathrm{CO}_{2}$, as carbon emissions are the most commonly used and enable comparison with other environmental studies, while at the same time, in this case study, yielding similar satisfaction scores as other measures of impact, such as environmental or human toxicity. These criteria correspond to the indicators for the material consumption $\left(\mathrm{I}_{5}\right)$, energy consumption $\left(\mathrm{I}_{6}\right)$ and $\mathrm{CO}_{2}$ emissions $\left(\mathrm{I}_{7}\right)$ caused by the tower's construction.

Requirement $\mathrm{R}_{3}$ includes three criteria (occupational hazards $\left(\mathrm{C}_{7}\right)$, perception $\left(\mathrm{C}_{8}\right)$ and technology integration $\left.\left(\mathrm{C}_{9}\right)\right)$. The occupational hazards criterion $\left(\mathrm{C}_{7}\right)$ assesses the probability of hazards affecting the workers $\left(\mathrm{I}_{8}\right)$ involved in the tower's transport, construction, maintenance or dismantling. This criterion was assigned a weight of $30 \%$, as the probability of accidents from heights is high. The perception $\left(\mathrm{C}_{8}\right)$ of the tower by the surrounding communities and users of nearby roadways includes the tower's visual and landscape impact as a result of its proportions $\left(\mathrm{I}_{9}\right)$ and the flexibility of the solution used $\left(\mathrm{I}_{10}\right)$ in terms of adaptation, contextualization and customization (Kieran, Timberlake 2004). Specifically, $I_{9}$ reflects the height-diameter ratio and subjective improvements to the tower's geometric proportions in keeping with how it is aesthetically perceived. In this regard, although lattice towers or even the precast concrete tripod presented in this paper may be more flexible and adaptable to different geometries and thus enable greater visual permeability, truncated and tapered forms seem to be more widely accepted. This criterion was assigned a weight of $60 \%$ and accounts for the majority of this requirement.

In contrast, $\mathrm{I}_{10}$ rewards the adaptability of the tower system to the particular needs of the costumer (particular and/or public). This is meant to consider, for instance, the better social acceptance of those alternatives that permit to customize the length of the pieces (reduce the length of the modules leads to lesser heavy transport requirements and, therefore reduction of traffic nuisances, better adaptability to the road infrastructure boundaries and minimization of the adequacy of the access). Finally, the integration of new technology $\left(\mathrm{C}_{9}\right)$ in any of the tower's design, installation or service stages is viewed positively, provided the new technology makes it possible to improve performance and maximize output. Thus, it includes $\mathrm{I}_{11}$, for which the maximum score is given when the technology in question is a patented innovation with regard to material or installation and/or monitoring processes.

This social requirement could also include additional indicators that make it possible to consider (1) total job creation, and (2) local consumption in terms of goods and services (e.g., accommodation and supplies) and materials required to build the support. However, these do not make substantial differences between different alternatives when an isolate wind - turbine is analyzed. That is, precast solutions demand less construction time 
(1-2 weeks) in comparison to those built in situ (more than three weeks); however, the formers require a greater number of workers during the construction period and, therefore, the ratio creation/duration of the job as well as the amount of consumption of local products is similar for the alternatives considered in this paper (Table 6). Likewise, the local consumption of materials to build the support is rather inexistent (this is usually transported to the construction site from the precast plants) provided that the distances are moderate and competitive from the economic and environmental points of view. In this sense, the $350 \mathrm{~km}$ considered in this study meets with these requirements (Engström et al. 2010).

Nevertheless, both aspects might be considered in case of either large wind farms or in those situations for which the installation of a temporary precast plant in the construction area is economically and/or environmentally justified (due to high transport distances, for instance). However, since this paper is focused on the assessment of isolated wind-turbine support systems, these indicators have been omitted.

This tree can be used to assess the sustainability index score for towers in other scenarios (different system constraints and/or social perceptions) and from the viewpoint of other stakeholders by adjusting the weightings and boundary conditions, accordingly.

\section{Case study: precast concrete tripod}

In this section the value functions for each of the 11 indicators in the requirement tree shown in Table 3 are defined. Likewise, the score for each indicator for the tower described in Section 2 is assessed.

The value functions make it possible to measure the degree (a dimensional) to which each alternative satisfies each indicator and associated criterion. The functions are defined by means of 5 parameters (Alarcón et al. 2011) that enable the determination of their shape and, thus, their sensitivity to variations in the indicator's value. To this end, the functions have different shapes: they may decrease concavely (DCv), decrease convexly (DCx), decrease linearly (DL) or have other shapes. For functions that decrease concavely, initial variations in the indicator's value will have a smaller impact on the satisfaction level than variations in the indicator's central values, to which they are more sensitive. In contrast, convex functions will be more sensitive to variations at the start, and with linear functions, variations in the indicator's value will be reflected through proportional variations in the associated degree of satisfaction. Once the value function for each indicator has been defined, the sustainability index score of each tower alternative can be determined. To this end, the additive formula shown in Eqn (1) must be applied to each tree level using the previously defined indicator values $\left(V_{i}\right)$ and weights $\left(\lambda_{i}\right)$ :

$$
V=\Sigma \lambda_{i} V_{i}\left(\mathrm{x}_{i}\right) .
$$

This additive formula, the value function equations, and their factors, as well as the value analysis schema, is common to all models designed based on the MIVES method. More information can be found in earlier papers that have defined similar sustainability analysis models for other areas (Lombera, Aprea 2010; Pons, Aguado 2012; Pons, de la Fuente 2013). However, the value functions for the 11 indicators (Table 4) of the requirement tree shown in Table 3 are specific to the sustainability analysis models for wind turbine towers presented here. The parameters and shapes of the value functions were also defined in the expert seminars, drawing on the references provided in the final column of Table 4.

Of the 11 indicators, 8 decrease concavely (DCv), 1 decrease convexly (DCx), and 2 decrease linearly (DL). $\mathrm{DCv}$ functions were chosen for indicators for which the client demands maximum satisfaction, such as economic aspects and minimizing occupational hazards. In contrast, DCx functions represent indicators for which the client will accept partial satisfaction, namely, those for energy consumption and emissions. The indicators with DL functions fall somewhere in between.

Table 4. Value function parameters for each indicator

\begin{tabular}{|c|c|c|c|c|c|c|c|c|}
\hline Indicator & Unit & $\mathrm{x}_{\max }$ & $\mathrm{xmi}^{\mathrm{n}}$ & $\mathrm{C}$ & $\mathrm{K}$ & $\mathrm{P}$ & Shape & Ref. \\
\hline $\mathrm{I}_{1}$. Direct cost & $€ /$ tower & $2,000,000$ & 900,000 & $1,100,000$ & 1.00 & 2.5 & $\mathrm{DCv}$ & Engström et al. (2010) \\
\hline $\mathrm{I}_{2}$. Cost deviations & points & 90 & 40 & 50 & 1.00 & 2.5 & $\mathrm{DCv}$ & Pons and Aguado (2012) \\
\hline $\mathrm{I}_{3}$. Maintenance work & $€ /$ tower $\cdot$ year & 10,000 & 4,000 & 5,000 & 0.05 & 2.5 & $\mathrm{DCv}$ & Pons and Aguado (2012) \\
\hline $\mathrm{I}_{4}$. Deconstruction & $€ /$ tower & 250,000 & 20,000 & 60,000 & 0.05 & 2.5 & $\mathrm{DCv}$ & ITEC (2014) \\
\hline $\mathrm{I}_{5}$. Material consumption & Tn/MW & 2,000 & 200 & 500 & 0.01 & 2.5 & $\mathrm{DCv}$ & Guezuraga et al. (2012) \\
\hline $\mathrm{I}_{6}$. Energy consumption & $\mathrm{GWh} / \mathrm{MW}$ & 1.5 & 0 & 0.75 & 1.00 & 2.5 & $\mathrm{DCv}$ & Ardente et al. (2008) \\
\hline $\mathrm{I}_{7}$. Emissions & ton $\mathrm{CO}_{2}-\mathrm{e} / \mathrm{MW}$ & 1,500 & 0 & 750 & 1.00 & 2.5 & $\mathrm{DCv}$ & Crawford (2009) \\
\hline $\mathrm{I}_{8}$. Occupational hazards & points & 2.5 & 1.5 & 2.5 & 0.01 & 3.0 & $\mathrm{DCv}$ & Pons and Aguado (2012) \\
\hline $\mathrm{I}_{9}$. Proportions & points & 100 & 0 & 100 & 0.01 & 1.0 & $\mathrm{DL}$ & de la Fuente (2007) \\
\hline $\mathrm{I}_{10} \cdot$ Customization & points & 100 & 0 & 100 & 0.01 & 1.0 & DL & Experts Seminar \\
\hline $\mathrm{I}_{11}$. New patents & points & 1 & 0 & 1 & 0.01 & 1.0 & DCx & Experts Seminar \\
\hline
\end{tabular}


Table 5. Values of the indicators $I_{i}$ for the new tower alternative (Section 2)

\begin{tabular}{|c|c|c|c|c|c|c|c|c|c|c|c|}
\hline Indicator & $\mathrm{I}_{1}$ & $\mathrm{I}_{2}$ & $\mathrm{I}_{3}$ & $\mathrm{I}_{4}$ & $\mathrm{I}_{5}$ & $\mathrm{I}_{6}$ & $\mathrm{I}_{7}$ & $\mathrm{I}_{8}$ & $\mathrm{I}_{9}$ & $\mathrm{I}_{10}$ & $\mathrm{I}_{11}$ \\
\hline Value & 242,015 & 90 & 6,545 & 120,200 & 560 & 0.49 & 100 & 1.82 & 90 & 60 & 1 \\
\hline Unit & $€ /$ tower & points & $€ /$ tower-year & $€ /$ tower & Tn/MW & GWh/MW & ton $\mathrm{CO}_{2}$-e/MW & points & points & points & points \\
\hline
\end{tabular}

Table 6. Satisfaction scores $V_{i}$ for requirements $R_{i}$ and indicators $I_{i}$ for the new tower alternative (Section 2)

\begin{tabular}{|c|c|c|c|c|c|c|c|c|c|c|c|c|c|c|c|}
\hline Indicator & $\mathrm{R}_{1}$ & $\mathrm{I}_{1}$ & $\mathrm{I}_{2}$ & $\mathrm{I}_{3}$ & $\mathrm{I}_{4}$ & $\mathrm{R}_{2}$ & $\mathrm{I}_{5}$ & $\mathrm{I}_{6}$ & $\mathrm{I}_{7}$ & $\mathrm{R}_{3}$ & $\mathrm{I}_{8}$ & $\mathrm{I}_{9}$ & $\mathrm{I}_{10}$ & $\mathrm{I}_{11}$ & Total \\
\hline Index $V_{i}$ & 0.57 & 0.83 & 1.00 & 0.33 & 0.38 & 0.64 & 0.60 & 0.44 & 0.88 & 0.64 & 0.31 & 0.90 & 0.60 & 1.00 & 0.62 \\
\hline
\end{tabular}

This value functions and associated parameters can be taken as reference; nevertheless, these can be adapted according to the preferences of the stakeholders involved in the decision procedure.

Table 5 shows the values for each indicator for the new tower alternative presented in Section 2. Table 6 shows the sustainability satisfaction scores for each indicator and requirement and the integrated overall score for the new tower solution explained in Section 2.

As can be seen from the results presented in Table 6, the overall sustainability index score $V$ of the tower alternative presented in Section 2 is 0.70 (out of a maximum score of 1.00), in accordance with the assigned weights (see Table 3). It is an appropriate result in terms of sustainability, and it shows that this alternative offers guarantees of success in the field of wind farm construction. Specifically, the economic requirement $\left(V\left(\mathrm{R}_{1}\right)=0.57\right)$ has the most moderate satisfaction score, due to the fact that the indicators for maintenance cost $\left(V\left(\mathrm{I}_{3}\right)=0.33\right)$ and deconstruction costs $\left(V\left(\mathrm{I}_{4}\right)=0.44\right)$ had relatively low scores, which penalized the overall score for this requirement. However, the environmental $\left(V\left(\mathrm{R}_{2}\right)=0.86\right)$ and social $\left(V\left(\mathrm{R}_{3}\right)=0.64\right)$ requirements yielded higher satisfaction scores and, in keeping with a more holistic view of sustainability, help to balance out the overall score. The higher satisfaction scores of the environmental and most social indicators is due to the fact that this tower alternative is a patented technology that has not yet been brought to market and that it has been designed to optimize the technical, environmental, social, etc., requirements. The economic and social indicators are expected to be improved in the future when the tripod is brought to market. In this regard, it is worth noting that this new system has the same advantages and disadvantages associated with precast concrete and steel construction.

The model has been quite useful for determining which indicators yield high satisfaction scores $-\mathrm{I}_{1}, \mathrm{I}_{2}$, $\mathrm{I}_{5-7}$ and $\mathrm{I}_{9-11}$ - and which ones need to be significantly improved $-\mathrm{I}_{3}$ and $\mathrm{I}_{4}$, for maintenance and deconstruction costs, and $\mathrm{I}_{8}$ for probability of accidents. On the whole, it can be concluded from the overall results that the proposed alternative has future potential in the field of wind turbine construction.

It must be borne in mind that the weights assigned to the requirements (Table 3 ) are meant to meet a balanced sustainability concept (case $1: \lambda\left(\mathrm{R}_{1}\right)=33.3 \%, \lambda\left(\mathrm{R}_{2}\right)=$
$33.3 \%$ and $\left.\lambda\left(R_{3}\right)=33.3 \%\right)$. However, these weights could be debatable during an economic crisis period or from the point of view of either a private wind farm owner or a precast concrete manufacturer investing in a new support system.

In this regard, two additional scenarios have been considered to verify both the robustness of the sustainability score obtained for the new system and the flexibility of the proposed model in terms of dealing with the different interests of the various stakeholders. To this end, a scenario in which the economic requirement is of moderate importance and the other two are assigned the same weight in the decision has been considered (case 2: $\lambda\left(\mathrm{R}_{1}\right)=50 \%, \lambda\left(\mathrm{R}_{2}\right)=25 \%$ and $\left.\lambda\left(\mathrm{R}_{3}\right)=25 \%\right)$. This weight distribution might correspond to a public investor that is affected by general economic constraints but nevertheless needs to address social and environmental aspects. Finally, a third scenario (case 3: $\lambda\left(\mathrm{R}_{1}\right)=75 \%, \lambda\left(\mathrm{R}_{2}\right)=$ $10 \%$ and $\left.\lambda\left(\mathrm{R}_{3}\right)=15 \%\right)$ in which the economic criteria is the most important and the other two have rather residual impact was considered. This scenario could reflect the preferences of a private investor analyzing the potential benefits of each alternative; however, it must be remarked that these weights would be inadequate concerning the sustainability since social and environmental aspects are treated as secondary.

The overall sustainability indexes obtained for each of these scenarios were 0.62 (case 1), 0.60 (case 2) and 0.58 (case 3 ). These results confirm that the support system proposed presents a slightly higher sustainability index in those cases for which social and environmental aspects are boosted (e.g., case 1). Besides, it can be noticed that these indexes are very similar, this reflecting the robustness of the support alternative designed for the different scenarios analyzed.

Above and beyond the results of the integrated sustainability analysis, it is important to stress the potential of the proposed model for analyzing wind-turbine support alternatives, as well as its versatility for simulating scenarios involving different stakeholder interests.

\section{Conclusions}

This paper has focused on the field of tall towers for large wind turbines. While, as noted, the market has already identified several alternatives in terms of construction 
procedure and/or materials, all have different specific advantages that, to date, have been difficult to integrate in a single alternative. Likewise, no reports of a systematic, robust and flexible method for choosing the most suitable and sustainable tower, from an integrated economic, social and environmental point of view could be found in the literature.

To address these needs, first, a new tall-tower solution was proposed for large wind turbines that integrates the positive aspects of both prefabrication (systematized production; strict control of materials, installation, and waste; versatile geometry; etc.) and, in particular, concrete (great structural rigidity, greater resistance to environmental agents, increased stability, and smaller foundation size). Moreover, a modular system was designed specifically for the proposed solution whereby all segments would have the same geometry and reinforcement configuration so as to contain transport costs and minimize the amortization period. There is still room for improvement in this alternative, although companies from the precast and wind power industries have expressed interest in the patented technology and in implementing it in real-life situations.

Likewise, a MIVES-method-based model for making decisions and conducting sustainability analyses was presented. The model can be used to assess the overall sustainability of wind turbine towers using the value functions strategy (satisfaction) to systematically and homogeneously weight aspects and needs of very different kinds. In particular, based on expert seminars, a requirement (3) and indicator (11) tree was designed, and the weightings proposed for a balanced concept of the sustainability were assigned. Thus, while the weightings reflect a specific analysis scenario, they can be calibrated to simulate different economic and social boundary conditions without the need to change the tree's structure. The same process can be carried out with the value functions. The model is thus suitable for analyzing wind turbine towers in general.

For example, here the model was used to assess the sustainability of the tower proposed in this paper, which is a patented technology that has not yet been brought to market. The results show that it is an alternative with potential, with an overall sustainability index score of 0.62 and scores for the main requirements of between 0.57 (economic), 0.64 (environmental) and 0.64 (social). The assessment enabled the identification of the indicators with the lowest satisfaction scores, namely, those for maintenance and deconstruction costs and for occupational hazards, which can now be corrected in the process of bringing the patented technology to market.

The sustainability index scores reflect the stipulated conditions for height $(100-120 \mathrm{~m})$, installed power (3.5 MW), and maximum transport distance $(350 \mathrm{~km})$. However, the proposed model can also be reliably used with other boundary conditions to obtain equally representative results by adapting the weights distribution and/ or the value function parameters.

\section{Acknowledgements}

The authors of this paper would like to express their gratitude to the experts from PRECON, S.A. who participated in the seminars to define the requirement tree. Likewise, the authors wish to thank the Bosch-Potensa Foundation for its financial support.

\section{References}

Agbayani, N. A; Vega, R. E. 2012. The rapid evolution of wind turbine tower structural systems: a historical and technical overview, in Proc. of Structures Congress 2012. Section: Advances in Analysis and Design of Wind Energy Structures, 1201-1212.

http://dx.doi.org/10.1061/9780784412367.108

Aguado, A.; del Caño, A.; de la Cruz, P.; Gómez, P.; Josa, A. 2012. Sustainability assessment of concrete structures within the Spanish structural concrete code, Journal of Construction Engineering and Management ASCE 138(2): 268-276.

http://dx.doi.org/10.1061/(ASCE)CO.1943-7862.0000419

Alarcón, B.; Aguado, A.; Manga, R.; Josa, A. 2011. A value function for assessing sustainability: Application to industrial buildings, Sustainability 3(1): 35-50.

http://dx.doi.org/10.3390/su3010035

Ardente, F.; Beccali, M.; Cellura, M.; Lo Brano, V. 2008. Energy performances and life cycle assessment of an Italian wind farm, Renewable and Sustainable Energy Reviews 12(1): 200-217. http://dx.doi.org/10.1016/j.rser.2006.05.013

Armengou, J. 2009. Support structure to wind turbines. Spanish Patent No. 7,123,455. Patents Spanish Office.

Crawford, R. H. 2009. Life cycle energy and greenhouse emissions analysis of wind turbines and the effect of size on energy yield, Renewable and Sustainable Energy Reviews 13(9): 2653-2660.

http://dx.doi.org/10.1016/j.rser.2009.07.008

CPH Comisión Permanente del Hormigón (Ministerio de Fomento). 2008. EHE-08 Instrucción del Hormigón Estructural. 25 p. (in Spanish).

del Caño, A.; Gómez, D.; de la Cruz, M. P. 2012. Uncertainty analysis in the sustainable design of concrete structures: a probabilistic method, Construction and Building Materials 37: 865-873.

http://dx.doi.org/10.1016/j.conbuildmat.2012.04.020

de la Fuente, A. 2007. New system of precast concrete towers for wind farms. Academic Project. Polytechnic University of Catalonia (UPC), Barcelona (Spain) (in Spanish).

de la Fuente, A.; Aguado, A.; Molins, C.; Armengou, J. 2012. Numerical model for the analysis up to failure of precast concrete sections, Computers \& Structures 106-107: 105114. http://dx.doi.org/10.1016/j.compstruc.2012.04.007

Engström, S.; Lyrner, T.; Hassanzadeh, M.; Stalin, T.; Johansson, J. 2010. Tall towers for large wind turbines. Report from Vindforsk project V-342 Höga torn för vindkraftverk.

Ernst, W.; Verlag, S. Structurae. Fuhrländer FL-2500 Windkraftanlagen des Windpark Spremberg [online], [cited 1 May 2014]. Available from Internet:

http://structurae.net/structures/data/index.cfm?id=s0060144

Gsänger, S.; Pitteloud, J. D. 2012. Report of the World Wind Energy Association (WWEA) 2011. Bonn, Germany.

Guezuraga, B.; Zauner, R.; Pölz, W. 2012. Life cycle assessment of two different $2 \mathrm{MW}$ class wind turbines, Renewable Energy 37(1): 37-44. http://dx.doi.org/10.1016/j.renene.2011.05.008

Hameed, Z.; Vatn, J.; Heggset, J. 2011. Challenges in the reliability and maintainability data collection for offshore wind turbines, Renewable Energy 36(8): 2154-2165. http://dx.doi.org/10.1016/j.renene.2011.01.008 
ITEC (Catalan Institute of Construction Technology). 2014. $B E D E C$. Barcelona: ITEC (in Spanish).

Herrando, V. 2012. Optimized design of reinforced concrete foundations for high height towers for wind turbines: Master thesis. Polytechnic University of Catalonia (UPC), Barcelona, Spain (in Spanish).

Kieran, S.; Timberlake, J. 2004. Refabricating architecture: How manufacturing methodologies are poised to transform building construction. New York: McGraw-Hill Professional. $175 \mathrm{p}$.

Lofty, A. 2012. Prestressed concrete wind turbine supporting system: MSc. Thesis. University of Nebraska, Lincoln, Nebraska, USA.

Lombera, J.-T. S-J.; Aprea, I. G. 2010. A system approach to the environmental analysis of industrial buildings, Building and Environment 45(3): 673-683. http://dx.doi.org/10.1016/j.buildenv.2009.08.012

Manwell, J. F.; McGowan, J. G.; Rogers, A. L. 2002. Wind energy explained. Theory, design and application. New York: John Wiley \& Sons LTD. 704 p. http://dx.doi.org/10.1002/0470846127

Mosalam, K.; Armengou, J.; Lee, H.; Günay, S.; Chiew, S. P. 2012. Performance-Based Engineering approach to the best decision for energy-efficient and sustainable building design, in First International Conference on Performancebased and Life-cycle Structural Engineering (PLSE 2012), 5-7 December 2012, Hong Kong, China. 13 p.

Nyström, B.; Söderholm, P. 2010. Selection maintenance actions using the analytic hierarchy process (AHP): decision - making in railway infrastructure, Structure and Infrastructure Engineering 6(4): 467-479.

http://dx.doi.org/10.1080/15732470801990209
Ormazabal, G.; Viñolas, B.; Aguado, A. 2008. Enhancing value in crucial decisions: line 9 of the Barcelona Subway, Journal of Management in Engineering ASCE 24(4): 265-272. http://dx.doi.org/10.1061/(ASCE)0742-597X(2008)24:4(265)

Pons, O.; Aguado, A. 2012. Integrated value model for sustainable assessment applied to technologies used to build schools in Catalonia, Spain, Building and Environment 53: 49-58. http://dx.doi.org/10.1016/j.buildenv.2012.01.007

Pons, O.; de la Fuente, A. 2013. Integrated sustainability assessment method applied to structural concrete columns, Construction and Building Materials 49: 882-893. http://dx.doi.org/10.1016/j.conbuildmat.2013.09.009

Reyes, J. P.; San-José, J. T.; Cuadrado, J.; Sancibrian, R. 2014. Health \& safety criteria for determining the sustainable value of construction projects, Safety Science 62: 221232. http://dx.doi.org/10.1016/j.ssci.2013.08.023

Saaty, T. L. 1990. How to make a decision: the analytic hierarchy process, European Journal of Operational Research 48: 9-26. http://dx.doi.org/10.1016/0377-2217(90)90057-I

United Nations (UN). 1992. Rio Declaration on Environment and Development [online], [cited 1 May 2014]. Available from Internet: http://www.unep.org/Documents.Multilingual/Default.asp?documentid=78\&articleid $=1163$

Villar, J. 2004. Project of foundation and high height concrete tower for wind turbine. Academic Project. Polytechnic University of Catalonia (UPC), Barcelona, Spain (in Spanish).

Vries, I. 2009. Concrete-steel hybrid tower from ATS, Renewable Energy World, September-October 2009, 109-111.

\begin{abstract}
Albert de la FUENTE. He is a Lecturer Professor of Concrete Structures at the Universitat Politècnica de Catalunya (Barcelona Tech.). His main research interests include development of multi-criteria decision-making tool, nonlinear analysis of concrete structures, optimization of fiber reinforced structures and its industrial applications.
\end{abstract}

Jaume ARMENGOU. He is the Vice-Chancellor for Academic Organization and Teaching Staff, Universitat Internacional de Catalunya. His main research interests are project management, business ethics and prefabrication of concrete structures.

Oriol PONS. He is Associate Professor of the Department of Construction at the Universitat Politècnica de Catalunya (Barcelona Tech.). His main research interests are innovative building technologies and their sustainability, LCA, software analysis, development and application to educational and curvilinear edifices.

Antonio AGUADO. He is Full Professor of the Department of Construction Engineering at the Universitat Politècnica de Catalunya (Barcelona Tech.). His main research interests are fiber reinforced concrete, shotcrete, self- compacting concrete, sustainability value analysis for integral and objective evaluation, concrete dams and tunnels. 